\title{
Streamline Control Forming Process Research of Key Part Pump Body of Diesel Engine
}

\author{
HU Chuan Kai ${ }^{1, a}$, KANG Feng ${ }^{1, b}$, NING Hai Qing ${ }^{1, c}$ and LIN Jun ${ }^{1, d}$ \\ ${ }^{1}$ Southwest Technique and Engineering Institute, Chongqing 400039, PR China \\ akaizihu@163.com, btiannakaff@163.com, nhq027@163.com, ${ }^{\mathrm{d}}$ cqlinjun@126.com
}

Keywords: metal streamline, forming, performance and control

Abstract. Metal streamline is the organization of fibrous distribution of impurities, compound, and segregation along main deformation direction on macro test block, which is of great influence on mechanics of members, use and process performance. Pump body is the key part of diesel engine which adopts longitudinal die splitting method to keep product in continuous state after processing. Although the process has increased technical difficulty and die wear, trimming can be produced only along lugs without overall trimming belt as with horizontal die splitting. Forgings with trimming cut basically keep continuous state as a whole, which greatly enhances performance of pump body.

\section{Introduction}

Metal streamline is the organization of fibrous distribution of impurities, compound, and segregation along main deformation direction on macro test block, which is of great influence on mechanics of members, use and process performance[1]. Good streamline makes better mechanical property of forging, whereas obvious defects on streamline such as cross flow, turbulent flow, cutoff and other phenomenon impair mechanical property of forging accordingly[2]. In forgings structure, performance is better along streamline direction than in the direction vertical to streamline[3]. Therefore in production of forgings, no only is streamline distribution required to be consistent with forging outline shape and structure as much as possible to avoid streamline outcrop in product processing, but also performance of product can be further improved if it is possible to make use of consistent stress state between streamline distribution and its real products [4].

\section{Process design}

Pump body is the key part in diesel engine (as shown in Fig. 1) which is made of 40CrMnMo structural alloy steel with complex shape and high dimension requirement. The original process adopts $\varphi 120 \mathrm{~mm}$ to directly process finished products. Processing is up to 45 processes with low utilization rate of material and low production efficiency. In addition, metal streamline in pump body structure is damaged specially at two lugs, where streamline cutoff and outcrop occur, which are quite unfavorable for pump body under a variety of alternating load with high requirement for performance. Now machining is designed to be done after hot precision forging. Since two lugs and square heads are not favorable for processing, structure dimension of upper part requires precision forging in place without dimension processing. Upper part in forging design without processing shall have draft angle within $0.5^{\circ}$ (see Fig. 2). 


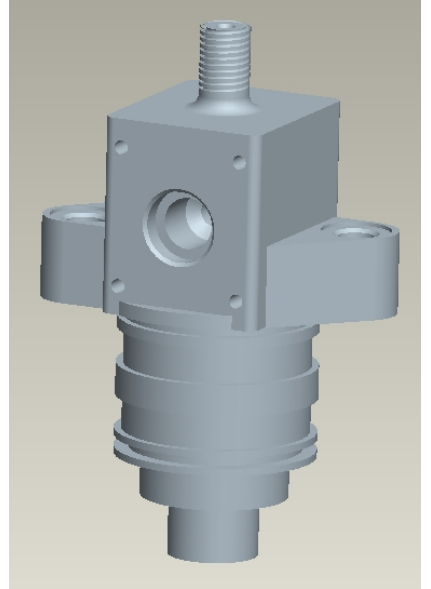

Fig.1 Pump body

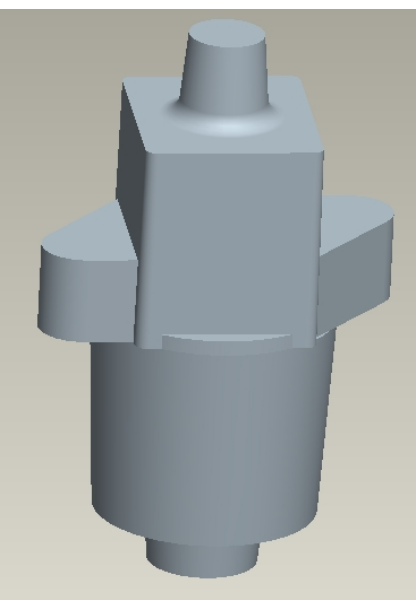

Fig.2 Forging of pump body

By process analysis, pump body forging may adopt two methods, namely, longitudinal die splitting (as shown in Fig. 3) and horizontal die splitting (as shown in Fig. 4). From process difficulty and die life, it is favorable to use horizontal die splitting process, with neither deep cavity dimension nor great draft force. Therefore workpiece can be easily taken out. However trimming around forgings may occur and joint may be left on streamline after trimming. In case of longitudinal die splitting, process difficulty has increased with deep cavity dimension while small draft angle, intensified die wear and increased ejection force, but the major advantage of the process is trimming will only be produce along lugs without overall trimming belt as with horizontal die splitting. Forgings with trimming cut basically keep continuous state as a whole, which greatly enhances performance of pump body. Since the part plays an important role in force bearing in engine, longitudinal die splitting process is confirmed to be adopted.

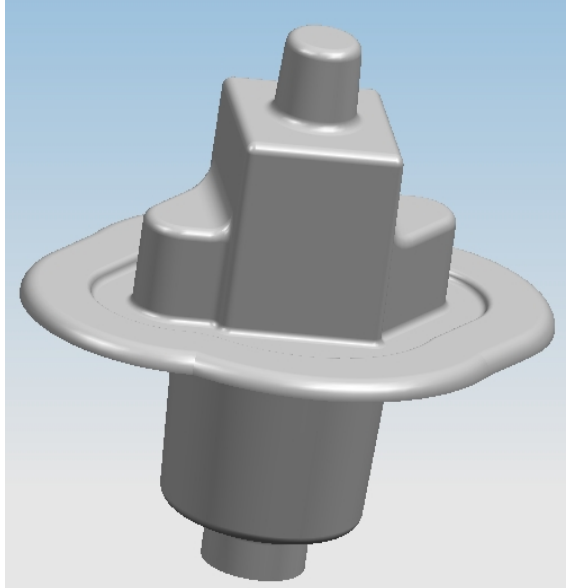

Fig.3 Vertical parting surface

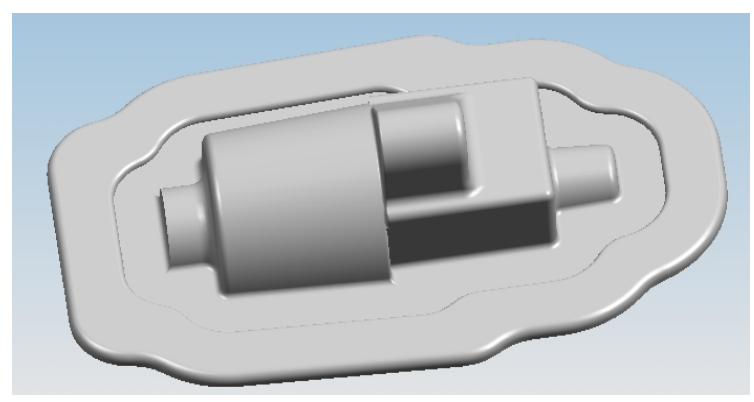

Fig.4 Horizontal parting surface

\section{Equipment requirements analysis}

Since some profiles are required to satisfy non-machining status, the forging is precision-grade forging. It is confirmed to adopt screw press for forming of main equipment while air hammer is required by auxiliary process for preparation of preformed blank and clipping press required for removing trimming of forgings. First, calculate tonnage requirement of main forming equipment according to empirical formula (1):

$$
\mathrm{P}=\mathrm{KS} / \mathrm{q} \text {. }
$$

Where coefficient $\mathrm{K}$ is $80 \mathrm{KN} / \mathrm{cm} 2$ according to experience in hot precision forging, total deformation area of forging $\mathrm{S}$ is calculated to be $17207 \mathrm{~mm}^{2}$ and deformation coefficient is 1.3 . After calculation, nominal pressure $\mathrm{P}$ is $8920 \mathrm{KN}$ and therefore $1000 \mathrm{~T}$ screw press is confirmed to be selected 
as main forming equipment. In addition, select $80 \mathrm{Kg}$ air hammer as blank forming equipment and closed double-point mechanical press as trimming equipment. According to process analysis and site equipment conditions, process flow of the pump forgings is preliminarily designed as follows: numerical control blanking $\rightarrow$ medium frequency induction heating $\rightarrow$ blank forming by air hammer $\rightarrow$ hot die forging forming by screw press $\rightarrow$ cutting by press $\rightarrow$ normalizing $\rightarrow$ shot blasting $\rightarrow$ cleaning.

\section{Die structure design}

Die structure of pump body forgings is designed according to longitudinal die splitting process, of which final forging die is shown in Fig. 5.

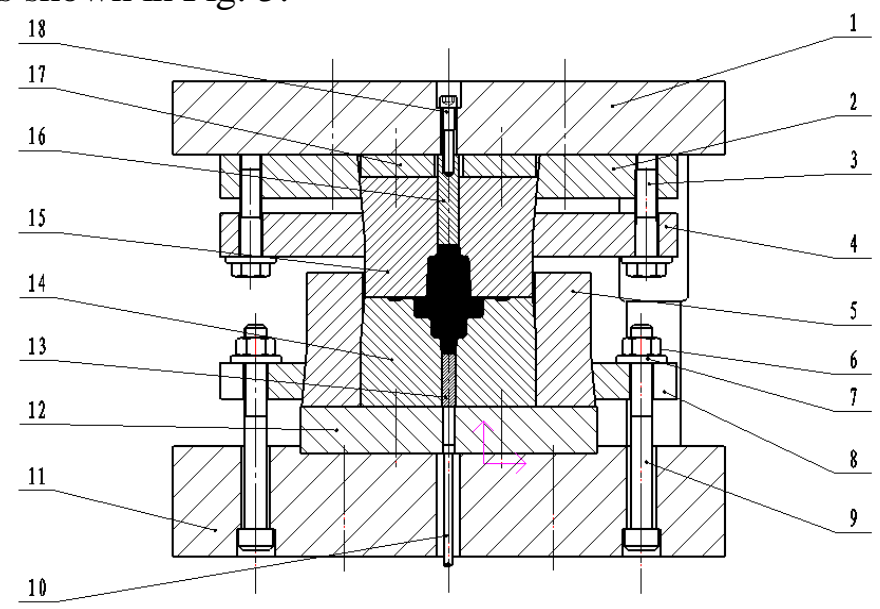

Fig.5 Hot die forging of the Pump body

In Fig. 5, adopt forming method of one downward forging square head for final forging die cavity. This is because on one hand, perform blank into square head shape for easy location at the time of being put into lower die cavity; on the other hand, one end of square head shape is non-machining surface with draft angle to be controlled within 0.5 degree. In case it is designed in upper die cavity, it will be difficult to eject, while it becomes easier with the help of ejecting force in case of lower die cavity. Since upper die cavity is machining surface with designed draft angle of 5 degree for easy ejection. In order to keep displacement between upper and lower dies within $0.5 \mathrm{~mm}$, the design adopts simultaneous action of "overall guide" and guide pin guide. Design guide pin hole in upper/lower die core as guide pin simultaneously with adopting guide pin and guide bush for the entire die to further ensure guide precision.

\section{Process test}

According to process analysis and die of design, forming process test has been conducted for pump body forgings, as shown in Fig. 6. The test is conducted on 1000 ton screw press with initial forging temperature of $1100 \square$. Spray water-based graphitic lubricant for lubrication. Prior to forging, adopt flame heating and thermal insulation for steel blank to ensure die temperature to be kept around 300 degree before forging. Adopt $80 \mathrm{~kg}$ air hammer to conduct square head blank forming for $60 \mathrm{~mm}$ bar stock. According to volume conversion, one end of square head is $65 \mathrm{~mm}$ long which is slightly shorter than forging to be easily put into die cavity. 


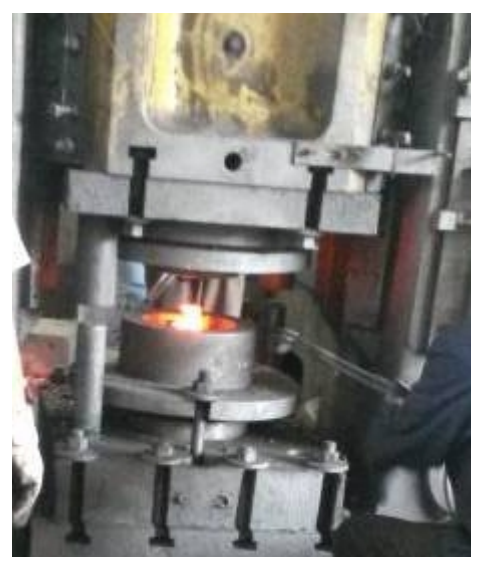

Fig.6 Engineering test of the Pump body

Result of first test is shown in Fig. 7. It can be seen in the first test, lugs at both sides of pump body folds (Fig. 7). Analysis shows it is because blank length of one end of square head is not adequate. When blank in put into final forming die cavity, it forms a step in transition area between square area and round area. After forming, the step is pressed into side lug to form fold. To solve the problem, by volume calculation, increase the length of preformed blank to $80 \mathrm{~mm}$ to conduct second process test. Thus the problem is solved as shown in Fig. 8.

It can be seen from final forging in Fig. 8, forging forms by longitudinal die splitting with trimming belt located under lugs, not affecting overall streamline of forging basically. After dimension test, dimension of pump body forging also conforms to technical requirements of products. Lugs on both sides are completely filled with no need for subsequent machining for some outer contour of square head end and lugs of forgings.

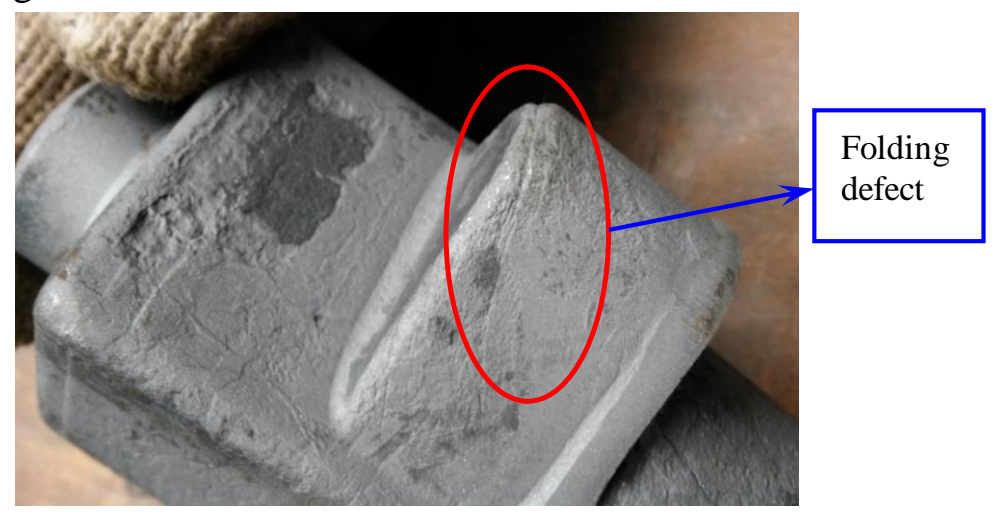

Fig.7 Folding defect on the pump body

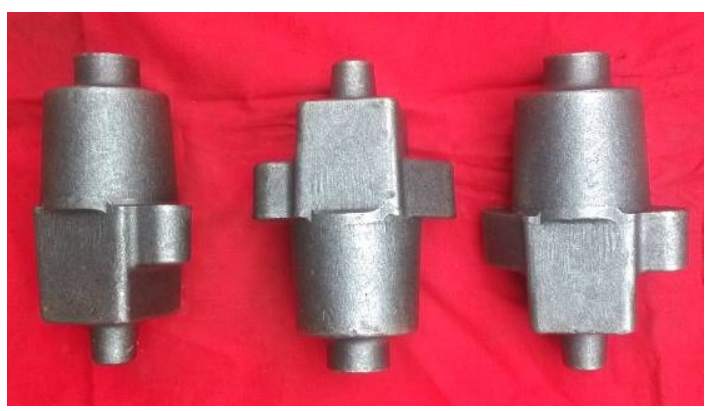

Fig.8 Sample of final forged pump body

Fig. 9 and Fig. 10 are cutting streamline analysis for forging. It can be seen overall streamline of pump body forging is basically continuous with only a little cutting in trimming belt. Streamline shows basically conformity with outer contour especially in lugs (Fig. 10). It can be considered use 
performance of pump body especially fatigue performance has greatly improve compared to horizontal die splitting or direct machining products.

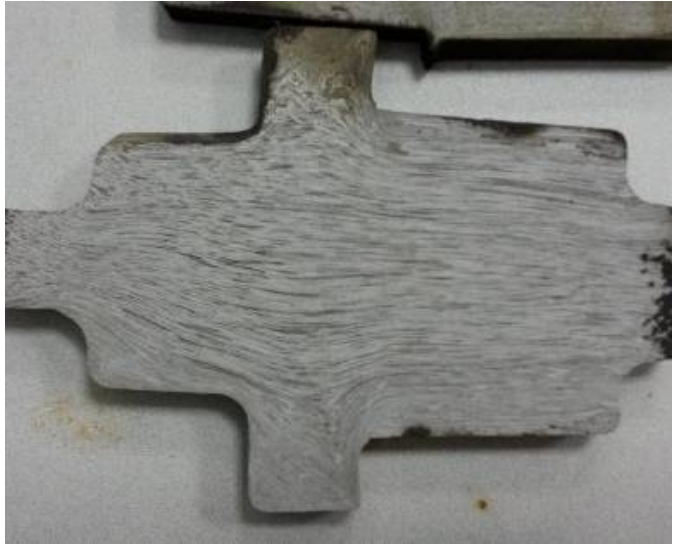

Fig.9 The metal fiber of the pump body

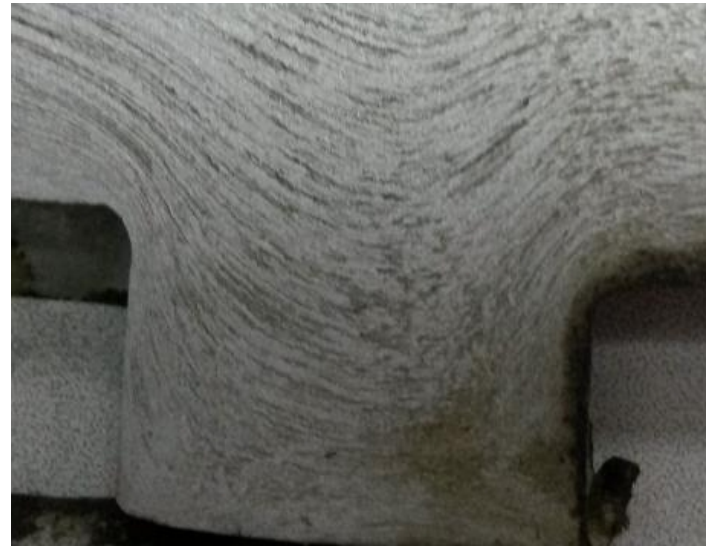

Fig.10 The metal fiber of the lugs

\section{Conclusion}

(1) For key parts for force bearing such as pump body, in order to keep continuous state of forging streamline, though process difficulty and die wear have increased adopting longitudinal die splitting method, trimming can be produced only along lugs without overall trimming belt as with horizontal die splitting. Forgings with trimming cut basically keep continuous state as a whole, which greatly enhances performance of pump body.

(2) Since there are obvious volume difference among preformed blank of complex parts, fold and other defects are easily produced in profiles with great changes during final forging. Test shows, the key approach to solve defects is to ensure adequate blank volume in position with most deformation without exceeding deformation extreme of length-diameter ratio of blank.

\section{References}

[1] GUO Ju-shou,YU Xia,LI Ai-ping and Sun Xiao-fei: Journal of Netshape Forming Engineering Vol.6-6(2014),p.111-115

[2]YE Huan-jun:Forge and Stamping Technology Vol.33-1(2008),p.91-92

[3]Cui Yiping,Wei Zhijian,Xia Yumin and Lu Yan:Heavy Casting and Forging Vol.2(2011),p.15-16

[4]XU Ping,WANG Xiao-ping:Machinery Design and ManufactureVol.9(2010),p.88-90 